\title{
REFLEXÃO E IMBRICAÇÃO DAS ATIVIDADES DA FIRMA COM SEUS VALORES DE USO E DE TROCA
}

\section{REFLECTION AND EMBEDDEDNESS OF ACTIVITIES OF THE FIRM WITH ITS USE VALUE} AND EXCHANGE VALUE

\section{Paulo Hayashi Jr}

paulo.hayashi@hotmail.com

Faculdade de Ciências Aplicadas - UNICAMP - Limeira - SP - Brasil

\author{
Nobuiuki Costa Ito \\ nobuiuki@hotmail.com \\ Faculdade de Economia Administração e Contabilidade da USP - São Paulo - SP - Brasil
}

\section{Fernando Antonio Prado Gimenez}

fapgimenez2009@hotmail.com

Escola de Administração - UFPR - Curitiba - PR - Brasil

\section{Resumo}

A firma existe com o propósito de criar valor de uso suficientemente adequado a ponto de ter valor comercial. 0 valor de troca deve não apenas pagar as atividades da firma como também gerar certos benefícios, financeiros ou não. Tanto o valor de uso quanto o valor de troca dependem das atividades da firma que são: procurar, manter, transformar e distribuir. Por sua vez, a estratégia deve envolver tanto o lado da criação quanto a proteção e a expansão do valor. Todavia, parece haver indícios de que a cocriação de valor por meio de uma participação mais ativa e colaborativa do consumidor tem permitido a algumas empresas obterem certa vantagem competitiva em relação a outras no mercado. Espera-se, neste trabalho, contribuir com o desenvolvimento do assunto por meio da análise dos valores, bem como dos níveis de produtos.

Palavras-Chave: Valor de uso. Valor de troca. Firma. Consumidor. Vantagem competitiva.

\begin{abstract}
The firm exists for the purpose of creating use value with commercial value. The exchange value should pay for the firm activities and also generate some financial and non-financial benefits. Both, use value and exchange value depend on the firm activities such as: finding, keeping, transforming and distributing. On the other hand, the organizational strategy should involve both, the creation side and also the value protection and expansion. Besides, the consumer participation and colaboration in the cocreation process have permitted some firms to obtain competitive advantages in relation to other traditional organizations.

The article tries to contribute with the development of the strategic field through value analysis and the linkage with the different product levels.
\end{abstract}

Key-words: Use value. Exchange value. Firm. Consumer. Competitive advantages. 


\section{Introdução}

Em artigo seminal de 1937, Coase questiona o "por quê" da existência da firma. E "por que não existe uma única grande firma no mercado?". O autor advoga que as firmas existem porque elas conseguem ser mais eficientes que o mercado na produção daquele item. E ainda, que não haveria uma única grande firma, porque ela não seria suficientemente eficiente se absorvesse toda atividade de coordenação e produção de todos os produtos (Coase, 1937). Assim, a pergunta inerente a toda firma é a clássica questão do make or buy decision. 0 que produzir na empresa? 0 que comprar de fora? Essa decisão era guiada pela economia dos custos de transação, ou seja, os custos positivos de ir ao mercado e transacionar aquilo que a empresa produz e/ou compra. Desta forma, as fronteiras da firma são definidas pela vantagem ou desvantagem da organização em relação a outras empresas que podem ser tanto organizações não mercado (hierarquia e contratos) quanto por mercado (Williamson, 1985, 1991a). A literatura que segue a Coase (1937) é conhecida por tratar o make or buy decision, em que a decisão estratégica para obtenção de rendimentos superiores - por meio de exercício de poder de mercado - passa longe da decisão de economizing em custos de transação (Williamson, 1991b).

Do ponto de vista estratégico, Hamel e Prahalad (1995) exploram com habilidade a questão por meio das competências essenciais. Por meio delas, a empresa foca naquilo que realmente importa para o negócio e também nas competências que ela possui que consiga distingui-las das demais. A miniaturização de empresas japonesas como a Sony, ou os motores da Honda são exemplos descritos pelos autores. A perspectiva da Resourced-based View (RBV) também focaliza na dimensão interna da firma, enfatizando que a obtenção e desenvolvimento de recursos idiossincráticos são a fonte de vantagem competitiva (Wernerfelt, 1984, Barney, 1991, Peteraf, 1993). A firma é uma entidade produtora ao realizar a transformação de insumos por meio de conhecimento, da habilidade da mão de obra, bem como pela tecnologia utilizada. Por outro lado, toda firma precisa também vender seus produtos no mercado de modo a pagar suas operações de fabricação e ainda, conseguir obter um surplus, uma recompensa para o crescimento das atividades. Deste modo, a questão do make or buy decision é intrinsecamente estratégica, uma vez que é decisiva para a estratégia corporativa, bem como para a formulação/formação de sua estratégia competitiva. Para Porter (1996), a estratégia reside na decisão de como relacionar atividades a serem realizadas de forma diferente dos rivais e, ainda, escolher quais atividades não fazer. Todavia, apesar de sua importância, o make or buy decision é pouco utilizado no campo estratégico, ainda que seja um conceito fundamental e que norteia a questão do valor.

Além disso, o conceito de valor é "aquilo que os compradores estão dispostos a pagar pelo que a empresa lhe oferece, ou seja, cada indivíduo estabelece o valor do produto ou serviço adquirido em função do benefício agregado por este produto ou serviço" (Porter, 1990, p.2), enquanto que, para Prahalad e Ramaswamy (2004, p. 169), o "valor está associado às experiências; os produtos e serviços facilitam experiências individuais e experiências medidas pela comunidade". De maneira ampla, valor é algo que pode ser desejado, necessitado, produzido e comercializado com possibilidades de lucro (Lepak; Smith; Taylor, 2007).

Assim, o presente artigo tem como objetivo analisar, refletir, argumentar, oportunizar e adaptar o encontro do make or buy decision com a criação e captura de valor, principalmente visando o desenvolvimento da literatura estratégica por meio de abordagens mais dinâmicas e relacionadas ao estado da arte do campo, tal como a cocriação de valor.

O principal benefício é conseguir destacar os pontos principais relacionados com o valor; sua 
criação, captura, defesa e uso. Adicionalmente, a reflexão sobre o tema permite um avanço concomitante sobre as nuances e detalhes do assunto. Para tanto, o artigo está dividido em cinco seções, sendo a primeira esta introdução. Segue-se, na segunda seção, a composição das atividades da firma e seus relacionamentos com o make or buy decision e também um detalhamento das atividades básicas da empresa. Além disso, com a terceira seção, é introduzido o consumidor como peça importante para a validação da própria questão do valor. 0 consumidor é o árbitro do valor tanto ex-ante quanto ex-post consumo. A seguir são realizados debate e aprofundamento da reflexão e imbricação das atividades da firma com seus valores de uso e de troca, sendo proposto um modelo de ligação estratégica entre fornecedor, firma e consumidor. Por fim, o artigo encerra-se com as considerações finais e também com as possibilidades futuras de pesquisa e desenvolvimento do tema.

\section{A Firma e Suas Atividades}

Para Mintzberg e Van der Heyden (2000), independente do setor e do tamanho, toda organização apresenta quatro atividades básicas: procurar, manter, transformar, vender.

A atividade procurar insere recursos, inputs, dentro da empresa, que podem ser tanto recursos tangíveis quanto intangíveis. Em setores com preços de venda pré-definidos ou com baixa elasticidade, o fator compra ganha importância sobre o próprio impacto na margem de contribuição e no lucro. Assim, por exemplo, para pecuaristas que trabalham na cadeia final de agregação de valor do boi, ou seja, na engorda, o preço de compra pode definir a própria lucratividade, uma vez que os preços finais de venda são relativamente estáveis e pré-definidos pelos frigoríficos juntamente com o mercado.

Já a atividade de manter significa armazenar os recursos adquiridos, produtos em processo e até mesmo estoques de produtos acabados. Algumas organizações se especializam nesta atividade, tal como os museus e aquários públicos, por exemplo. Uma das grandes questões desta atividade é saber o que tem no estoque e também o uso e movimentação adequada de modo a melhorar a produtividade sem perda ou desvalorização do valor da matéria-prima, componentes e outros insumos.

Por sua vez, a transformação é a atividade emblemática da indústria. Ela nos remete diretamente à questão da agregação de valor e à própria industrialização de matéria-prima em produtos acabados. Entretanto, a transformação existe não apenas na indústria, apesar de ser nela a parte mais visível, mas também no comércio com o fracionamento e venda em pequenas unidades principalmente.

A venda ou distribuição, por outro lado representa a saída dos produtos e recursos da firma com destino aos clientes e outros usuários. Nela estão envolvidos tanto aspectos de logística quanto de vendas. Com o desenvolvimento do comércio eletrônico, empresas do ramo de distribuição tal como os Correios, DHL, FedEx precisam acompanhar o ritmo de expansão para não se tornarem o gargalo no processo de compra online.

Todas estas atividades se tornam relevantes para o estudo do valor e da vantagem competitiva, uma vez que é por meio delas que há a construção, validação e sustentação dos mesmos, bem como as decisões e ações de make or buy.

A Figura 1 permite uma avaliação geral da relação entre make or buy decision e as atividades procurar, manter, transformar e vender (Mintzberg; Van der Heyden, 2000). As atividades procurar e vender referem-se às relações da firma com outras organizações, o que coloca a transação no centro da discussão. Já as atividades de armazenar e transformar estão relacionadas com as competências, capacidades e recursos que a empresa emprega no 
processamento de seus inputs na obtenção dos outputs. Na tentativa de relacionar a decisão de make or buy e as atividades da empresa com a questão do valor, pode-se indicar que dois mecanismos de criação de valor estão presentes: criação de valor de troca e criação de valor de uso.

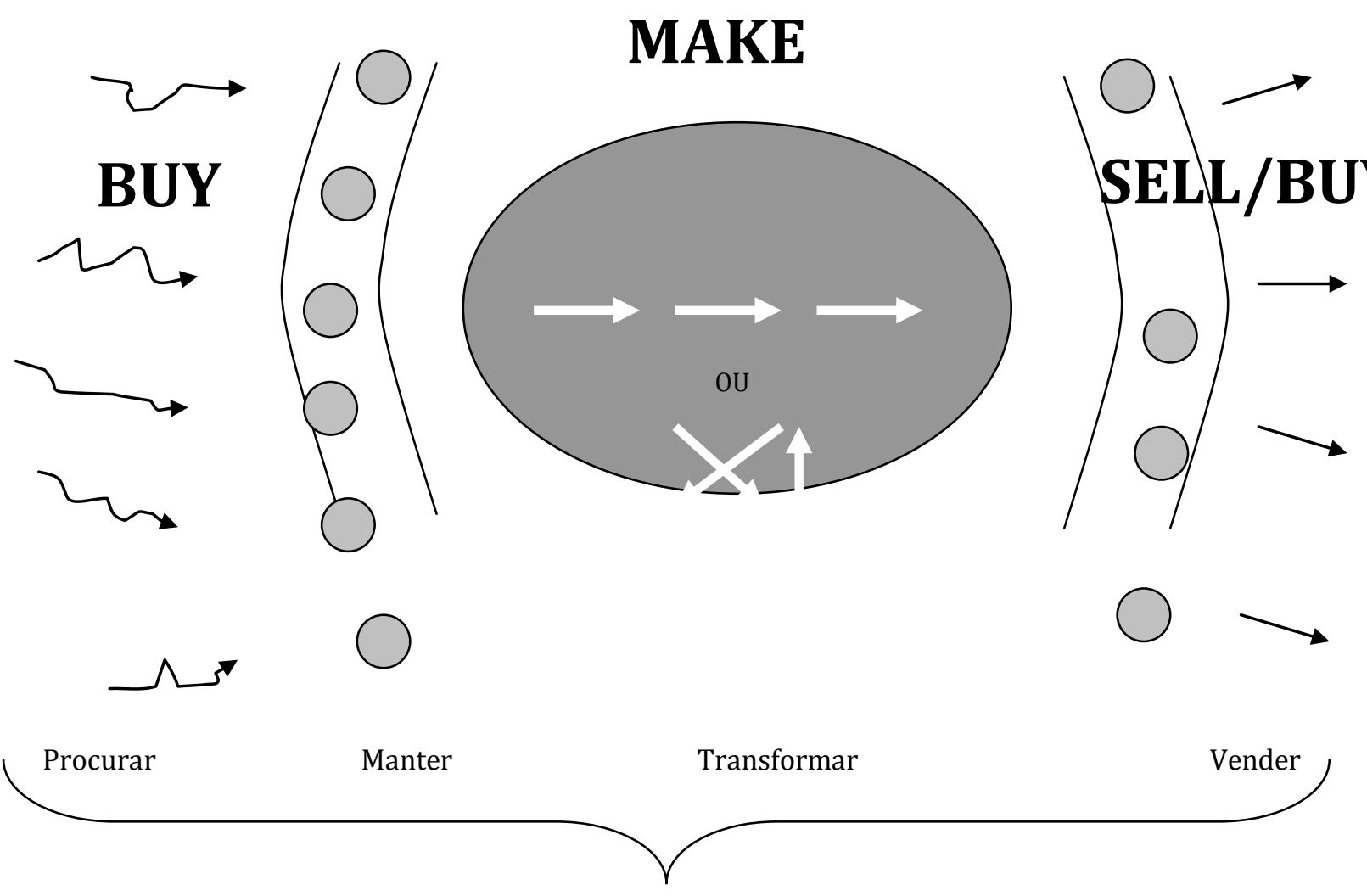

Visão Geral

Figura 1 - Atividades comuns de uma organização

Fonte: adaptado de Mintzberg e Van der Heyden (2000)

Primeiro, considera-se a criação de valor de troca. Coase (1937), Williamson (1991a) e seguidores afirmam que a firma existe para economizar custos de transação e o valor criado é fruto da não-dissipação de valor pela escolha de uma forma organizacional (mercado, contratos ou hierarquia) mais adaptada. Ou seja, se a forma organizacional mais indicada é contratos e o mercado é utilizado, evita-se atritos nas relações pela alteração do modo organizacional, o que cria valor pela não ocorrência, ou menor ocorrência, de atritos relacionais (economia dos custos de transação). Esses são aspectos relacionais entre agentes que abrangem as transações, suas características e suas soluções organizacionais.

O valor de troca, nesse sentido, é afetado pelos custos de transação, pois o modo de governança da relação mais adaptada às características da transação gera maior valor na troca. 0 mecanismo de criação de valor de troca é, portanto, influenciado pela economia dos custos de transação no diz respeitos às atividades de procurar e distribuir.

Entretanto, o debate da Economia dos Custos de Transação não abrange a questão estratégica, por considerar que economizar custos de transação é mais efetivo que as ações estratégicas fundamentadas na organização industrial: "economy is the best strategy" (Williamson, 1991b, p. 75). Contradizendo essa afirmativa, Porter (1980), no seu modelo das cinco forças, analisa o posicionamento da empresa em relação a fornecedores, rivais, entrantes potenciais, produtos 
substitutos e compradores. Situações de assimetria de condições de barganha influenciam na proteção do valor contra capturas externas ou mesmo possibilita a captura de valor criado por outrem. 0 posicionamento na indústria também influencia nas atividades de procurar e vender, o que determinará o valor de troca.

Em segundo lugar, passa-se a considerar a criação do valor de uso. 0 valor de uso é fruto da necessidade que o produto gera na vida dos compradores e, então, a maneira óbvia de sua criação envolve o processo produtivo. Os recursos utilizados, as competências na identificação das necessidades, quiçá na criação das necessidades nos consumidores, e a habilidade de desenhar e montar um produto que reflita todo esse emaranhado de variáveis estão presentes nas atividades internas da firma; nas atividades de armazenar e transformar. A RBV é uma lente teórica que possibilita analisar esses aspectos, seja pelo desenvolvimento de recursos valiosos, raros, difíceis de imitar e substituir e aproveitados pela organização (Barney, 1991, Barney; Hesterly, 1998) ou pela capacidade de responder à dinâmica do ambiente (Teece; Pisano; Shuen, 1997). As atividades armazenar e transformar são o cerne do processo produtivo e contribuem de forma determinante na criação de valor de uso.

A criação de valor de uso pode também estar ligada com as relações da empresa com as organizações no entorno, ou a montante ou a jusante da cadeia. As atividades de procurar e distribuir podem informar sobre a seleção dos fornecedores e distribuidores. A qualidade, marca ou especificidades dos inputs podem ser críticos na criação de valor de uso no processor produtivo. Entregar o produto no lugar e momento certos, por sua vez, também podem significar fatores essenciais na criação de valor de uso. Outrossim, um último aspecto, também fundamentado na RBV, é importante que os recursos sejam protegidos por mecanismos de isolamento (Rumelt, 1984), tais como condições históricas únicas (Dierickx; Cool, 1989; Barney, 1991), incertezas de imitabilidade (Lippman; Rumelt, 1982) e ambiguidade causal (Derickx; Cool, 1989; Lippman; Rumelt, 1982; Barney, 1991), que agem como garantidores que o valor de uso criado não seja apropriado e explorado por outras empresas.

Além disso, é importante distinguir os valores em valor de uso e valor de troca. 0 valor de uso é implícito ao produto ou à utilidade do mesmo, enquanto que o valor de troca é a expressão monetária do objeto trocado. Desde Adam Smith, há a observação de que os produtos possuem esta face dupla de valor (valor de uso e valor de troca), sendo que muitas vezes não são diretamente proporcionais. Smith (1983) cita o caso da água e do diamante. Muitos produtos com baixo valor de uso possuem alto valor de troca, enquanto que produtos como a água, com alto valor de uso, apresentam baixo valor de troca. Assim como no caso da moeda e sua dupla face, também há este aspecto em relação às próprias atividades da organização. A empresa ao 'procurar' o mercado e adquirir determinados recursos, ela está comprando tanto pelos valores de uso intrínsecos quanto pelos valores de troca envolvidos.

Se os valores de troca forem altos demais, talvez um produto substituto seja procurado ou então, até mesmo a desistência por completo da operação. Por outro lado, é possível que a empresa consiga barganhar no preço, com isso há o que se pode chamar de captura de valor. Ou seja, ela conseguiu obter um recurso com valor de uso através de um valor de troca inferior ao preço de mercado. Para quem vendeu, houve uma perda relativa, apesar de que o fornecedor espera manter uma relação de parceria ou de relações comerciais por um período de tempo longo.

Já na atividade de manutenção a questão fundamental é evitar a perda de valor por meio do uso inadequado ou falta de conservação dos recursos. Também, em algumas situações, pode-se esperar que haja o aumento do valor por meio da manutenção. Por exemplo, quem compra uma 
obra de arte e espera ganhar dinheiro com a sua valorização devido ao aumento da raridade ou então a valorização do próprio artista, almeja o aumento do valor de troca, ainda que o valor de uso possa continuar o mesmo. Outro exemplo são vinhos produzidos em grandes safras e que ganham cada vez mais qualidade devido ao descanso em barricas de carvalho ou até mesmo o repouso das garrafas durantes um longo período de tempo. A atividade de manutenção, neste caso, é essencial para o ganho tanto de qualidade técnica quanto de apelo comercial e reputação. Por sua vez, na transformação, o valor de uso sofre alterações com agregação de novas características e também novos valores de troca. Um produto industrializado não representa necessariamente a soma individual das partes dos componentes. Há uma verdadeira alquimia de transformação durante este processo. Ou seja, com a transformação mudam-se de patamares os valores de uso e de troca em relação à matéria-prima ou aos recursos anteriores à transformação.

Por sua vez, na atividade de distribuição será necessário proteger os valores de troca, evitando que se perca valor com compradores fortes demais e também aumentar a própria barganha da empresa, fazendo com que haja um ágio do valor de troca em relação ao próprio valor de uso do produto. Assim, questões competitivas e de manutenção das vantagens competitivas passam por uma espécie de 'puxa e repuxa' de valores (de uso e de troca) nas diferentes atividades existentes em uma organização; algumas fazem o valor aumentar (captura e criação), outras fazem o valor diminuir (perda). 0 balanço final é que será importante, podendo a empresa perder em algumas situações e etapas, desde que, globalmente, acumule de forma positiva. Caso contrário, a operação geral da empresa não será sustentável.

Assim, a questão dos valores é de grande importância para o desenvolvimento da própria organização. Todavia, não parece haver um consenso acerca de como os acadêmicos observam e trabalham o tema. Em um fórum especial da Academy of Management Review sobre criação e captura de valor, os editores Lepak, Smith e Taylor (2007) apontam que a principal conclusão do mesmo é a falta de acordo entre os diferentes teóricos devido às diferentes formações e backgrounds dos colaboradores. Assim, é possível utilizar diferentes "lentes" acadêmicas para se trabalhar com a questão do valor, tais como: a sociológica, a econômica, a ecológica, psicológica e o da administração Deste modo, apesar de haver grande interesse pelo assunto, a questão do valor e de como utilizar estratégias e ações que maximizem o valor e diminuam os riscos para a organização, ainda está em um nível incipiente; há poucas discussões e tampouco conclusões e recomendações acerca do assunto. Todavia, para a construção da vantagem competitiva sustentável é necessário que haja uma associação positiva das várias atividades da firma, principalmente nos pontos de transformação e transação, seja construindo e agregando valor, sendo defendendo ou capturando valores de terceiros. Assim, o Quadro 1 auxilia na construção de um mapa em direção à vantagem competitiva sustentável.

\begin{tabular}{|c|l|c|c|}
\hline Atividade & \multicolumn{1}{|c|}{ Visa } & Ação & Valor preponderante \\
\hline Procurar & $\begin{array}{l}\text { Recursos com alto valor de uso, mas } \\
\text { baixo valor de troca }\end{array}$ & Capturar valor & Valor de Troca \\
\hline Manter & Evita a perda de valor & Criar Valor & Valor de Uso \\
\hline Transformar & Gerar novo valor de uso & $\begin{array}{l}\text { Capturar Valor } \\
\text { Proteger Valor } \\
\text { Distribuir } \\
\text { apropriação de Troca } \\
\text { compradores indevida pelos }\end{array}$ \\
\hline
\end{tabular}

Quadro 1 - Atividades organizacionais e a criação, captura e proteção dos valores 
Como vimos anteriormente, cada uma das atividades da organização representa uma etapa importante para a construção ou defesa do valor. Está implícita no quadro 1 uma certa preponderância dos valores de troca nas fronteiras da firma, enquanto que o valor de uso tem maior representatividade nas atividades internas. De certo modo, pode-se começar a instigar a aproximação ou a união da abordagem estratégica da Visão Baseada em Recursos (VBR) com a Teoria dos Custos de Transação (TCT), uma vez que a primeira tem um foco maior no valor de uso e na empresa produtora, enquanto que a TCT, como o próprio nome indica, com a transação e o valor de troca.

\section{Procurando Valores}

A empresa é um sistema aberto e, portanto, realiza trocas com o meio no qual está inserida. Uma das trocas mais importantes é o de comprar aquilo que necessita, pois não tem condições de produzir por si só. É a questão do make or buy decision ou da grande firma de Coase (1937). Por exemplo, é clássica a história de integração vertical realizada por Henry Ford, que produzia desde borrachas no Amazonas até fábricas de aço para a construção de seus carros. Todavia há muitas dificuldades e complexidades interligadas a tal tipo de estratégia. Atualmente, a questão das competências essenciais tem levado as empresas a repensarem em suas estratégias corporativas de atuação de modo a ficarem focadas naquilo que elas são realmente boas e que seja representativo para o mercado. Talvez um dos casos mais emblemáticos é a própria saída da IBM do mercado de computadores pessoais. Para a empresa, o núcleo de seu negócio está em atuar como prestadora de serviços de resolução de problemas para seus clientes na área de gerenciamento de dados e informação e não mais na montagem de computadores pessoais.

Vale a pena a organização investir naquilo que realmente importa. Deste modo, a aquisição de recursos com valor de uso úteis para a organização representa aspecto valioso para a estratégia global da firma. Todavia, é necessário capturar valor, ou seja, é necessário tentar "pagar menos" por aquilo que compra. Assim, a vantagem competitiva está ligada à atividade de procurar e de capturar valor dos fornecedores. Setores como o supermercadista, aonde existem grandes players mundiais, também se beneficiam das negociações com os fornecedores para a construção de sua vantagem competitiva. Assim, práticas como bonificação, aluguel de gôndola, cobrança por cadastro de novos produtos são formas que os supermercados capturam valor dos fornecedores. Outro aspecto é ter marcas próprias dos supermercados como uma forma de fortalecer suas negociações e o poder de barganha, principalmente para com os fornecedores mais fortes.

Todavia, além da busca por valores, também é necessário que a empresa saiba mantê-los de forma adequada, sem a sua perda, desperdício, ou desvalorização.

\section{Mantendo Valores}

Algumas organizações como museus, aquários públicos, bibliotecas apresentam a atividade de manter como uma de suas principais formas de interagir com a sociedade.

Na questão dos valores com os recursos e insumos comprados, é necessário que tais recursos não percam os valores embutidos neles. Assim, a atividade de manter se torna relevante, principalmente quando o valor de troca do produto é alto. A classificação dos produtos e insumos em categorias A, B e C são formas de distinguir a necessidade de atenção para itens diferentes da empresa. Produtos do tipo A são aqueles mais valiosos e que costumam representar a maior parte do dinheiro investido. São o 'carro-chefe' ou os produtos com maior destaque. Produtos do tipo A costumam ser relacionados à clássica regra de Pareto, conhecida como 80,20 . Ou seja, $80 \%$ do valor do dinheiro investido em mercadorias estão em apenas $20 \%$ 
dos produtos. Ou então, $20 \%$ dos produtos representam $80 \%$ do faturamento, etc.

Por outro lado, produtos do tipo B são aqueles com valor mediano e produtos C são os que ocupam talvez mais espaço ou roubam mais tempo do operador e que representam apenas $20 \%$ do valor.

É preciso que produtos do tipo A recebam uma atenção maior quanto à busca e à proteção de valor do que os produtos B e C. Todavia, muitas vezes é nos detalhes com os produtos $C$ que se geram grandes diferenças na transformação da matéria-prima. Como diria o consultor de empresas Tom Peters (2011), é nos detalhes que as empresas constroem sua reputação e vantagem competitiva.

\section{Transformando Valores}

A transformação dos recursos e insumos em um novo produto gera ou cria novos valores de uso; é a popular expressão "agregação de valor". Por outro lado, com a mudança dos insumos e componentes para um novo produto também se gera um novo valor de troca.

De maneira geral, a atividade de transformação é facilmente perceptível no setor industrial. Por outro lado, no comércio e nos serviços tal atividade, apesar de não ser tão óbvia como na indústria, também ocorre e gera mudanças na configuração do valor de uso e de troca. Os supermercados, por exemplo, compram grandes quantidades e fracionam em pequenas unidades para venda. Os serviços, por sua vez auxiliam na satisfação de necessidades específicas de seus clientes, mesmo não gerando um produto tangível propriamente dito.

0 valor de uso representa não apenas a parte material, mas também os benefícios inerentes ao produto e serviço. De maneira semelhante, a abordagem da Visão Baseada em Recursos (VBR) procura não apenas destacar os pacotes de benefícios envolvidos com os recursos, mas também enfatizar a importância dos recursos intangíveis em relação aos tangíveis (Penrose, 1995). Assim, recursos como a reputação e os relacionamentos estratégicos com outras organizações têm sido fundamentais para o desenvolvimento de novos produtos (Verona, 1999). Além disso, esses recursos auxiliam na obtenção de melhores condições de ir ao mercado e obter captura de valor por meio da força da empresa na hora da venda.

Não adianta apenas a empresa ser uma boa organização produtora, é preciso também ter habilidades para ir ao mercado e transacionar de modo a evitar a perda de valor e, por outro lado, buscando também incrementar o valor de troca.

\section{Vendendo Valores}

A empresa precisa agora vender bem seus produtos no mercado. Saber vender significa realizar a transação de modo a dispor seus produtos em troca de recompensas monetárias. Já "vender bem" implica na maximização da captura de valor no mercado, ou seja, na obtenção de alto valor de troca, o que nem sempre é possível, pois o preço da mercadoria não é totalmente dependente da empresa. Assim, mesmo que a empresa queira nem sempre é possível maximizar o preço de venda, sendo elemento importante os mecanismos de proteção do valor, evitando que o valor se esvaia. Outro aspecto importante na atividade de distribuição é a logística por trás do negócio. Por exemplo, o site de vendas online DealExtreme tem como uma de seus atrativos o frete gratuito de seus produtos para qualquer parte do planeta. Assim, com a logística afinada, as suas operações de transformação e de transação contribuem para que a empresa não apenas fique isenta de grandes competidores diretos devido ao volume necessário para que outra empresa inicie operações no mesmo ramo (barreira de entrada), como também reforça o posicionamento da organização como uma varejista de classe mundial. 


\section{Envolvendo o Consumidor}

Além das atividades de procurar, manter, transformar e vender, a vantagem competitiva para ser sustentável também dependerá de elementos próprios do consumidor. Assim, o consumidor co-participa na construção e validação da vantagem competitiva da firma. Para Prahalad e Ramaswamy (2000), isso significa envolver e cooptar as competências, o conhecimento e a habilidade dos próprios consumidores. Com isso, parte-se do pressuposto que a criação de valor não é feita única e exclusivamente pela empresa produtora. Pelo contrário, ao se colocar o consumidor em cena, faz-se uma ligação estratégica importante em não subordinar os interesses do mercado às visões e percepções da empresa sobre o próprio mercado. Deste modo, é o próprio consumidor que tem voz e reconhece, premiando ou punindo, aquelas empresas que estão mais alinhadas com ele. Além disso, pode-se dizer que há muita semelhança com as atividades de procurar e transformar da firma com as do consumidor. Na sequência se examina tal questão do consumidor, antes e depois da compra e do consumo.

\section{Ex Ante Consumo: o Lucro do Consumidor}

De maneira geral, toda transação depende não apenas do vendedor e do comprador, mas também daquilo que se costuma chamar de "custo x benefício" do produto. Ou seja, é a avaliação do preço praticado versus os benefícios ou a qualidade e os valores embutidos no produto, bem como os valores praticados pelos concorrentes. Para o vendedor, a melhor escolha possível seria oferecer o maior preço com o menor custo total. Já para o lado do comprador, seria a busca e a obtenção da melhor qualidade com o menor preço. Assim, há um certo conflito de interesses entre as partes sendo necessário encontrar um ponto intermediário entre esses extremos para que se realize a transação. Não sendo possível a maximização, é preciso encontrar um ponto satisfatório para ambos para que ocorra a transação.

Para Bach et al. (1987), os compradores procuram escolher os produtos que proporcionam maior lucro e satisfação para eles. O lucro do consumidor é a diferença entre o valor total percebido no produto e o seu preço real praticado. Caso haja percepção pelo consumidor de que o produto está subvalorizado em relação ao preço real, então o consumidor se sente no lucro. Por exemplo, uma bolsa que costuma ser vendida a $\mathrm{R} \$ 300$ em qualquer loja e em qualquer época do ano, uma consumidora encontra em uma ocasião o mesmo produto pela metade do preço devido ao fechamento do estabelecimento. Consciente do preço de mercado, para a consumidora há a formação de seu lucro em $\mathrm{R} \$ 150$, ou seja, ela vai economizar este valor, pois não encontrará em nenhuma outra loja um preço como este.

A respeito da avaliação dos produtos pelos consumidores, eles fazem inferências sobre os produtos a partir de uma variedade de "pistas". Para Schiffman e Kanuk (2000), a percepção dos consumidores sofre influencia da aparência física, dos estereótipos, os sinais irrelevantes ou pequenos, as primeiras impressões, as conclusões precipitadas e, ainda, o efeito halo. Este último implica na avaliação de uma ou poucas dimensões do produto, ou seja, o consumidor faz um "salto indutivo", considerando como geral o que se avaliou no particular.

Apenas ilustrando, no caso específico do vinho pode ser desde o formato e peso da garrafa, bem como o tipo de rótulo (plástico, papel brilhante, papel vergê, papel com letras douradas, etc), figuras (brasão, medalhas, desenhos como castelos, caves, etc), informações técnicas, entre outras (Bowman; Ambrosini, 2000).

A percepção dos consumidores está baseada em suas crenças a respeito do produto, suas necessidades, experiências, desejos, conhecimentos, produtos substitutos disponíveis, contextos de compra e uso e expectativas (Bowman; Ambrosini, 2000; Schiffman, Kanuk, 2000). Já para 
Hunt e Morgan (1995), a percepção dos consumidores sobre o valor do produto depende: 1) dos gostos e preferências e 2) dos recursos que produziram o produto. Este último ponto conflita tanto com Bowman e Ambrosini (2000) quanto com Prahalad e Ramaswamy (2000), pois os consumidores podem avaliar apenas aquilo que percebem e que conhecem. Assim, seria difícil para o consumidor avaliar um produto pelas técnicas de kanban utilizadas no processo, por exemplo. Outra questão apontada por Dodds et al. (1991), é a influência do lojista e da marca na avaliação do valor percebido pelo consumidor. Lojas mais arrumadas e marcas mais reconhecidas favorecem a percepção da qualidade e do valor do produto. Assim, o caráter do valor como aspecto mais intrínseco à produção ou à indústria acaba se tornando elemento complexo de análise e de operacionalização, tendo em vista a necessidade de incluir agora a avaliação do valor pelo consumidor.

Deste modo, a questão do valor de uso, valor de troca e valor percebido pelo consumidor formam a relação apresentada na Figura 2.

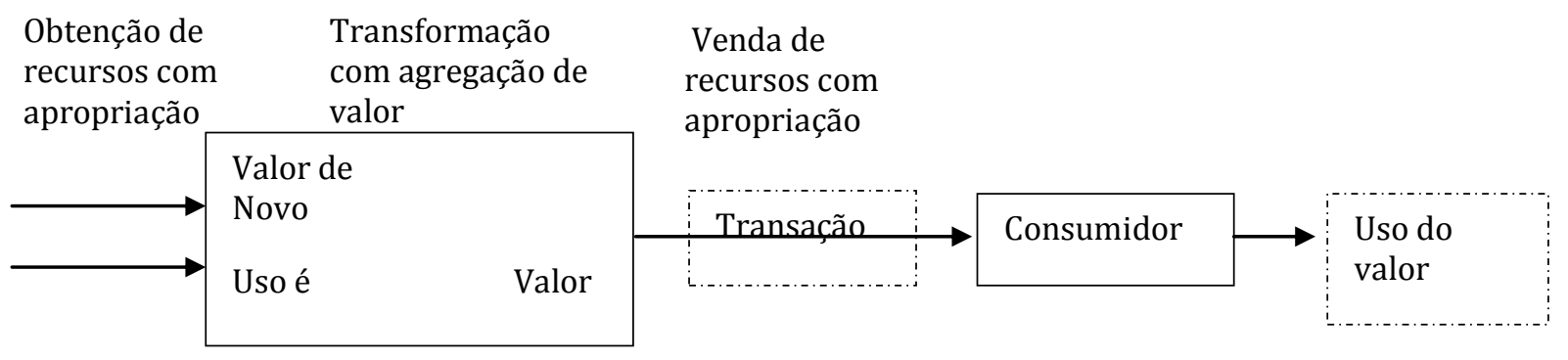

Tempo

Figura 2 - 0 processo de criação de valor

Fonte: Bowman; Ambrosini (2000, p. 8)

A questão da vantagem competitiva da firma vai além da questão competitiva (setor industrial, competidores), bem como de elementos internos da firma (recursos, capacidades, ativos, habilidades, competências). A questão do uso do valor do produto pelo consumidor também influencia, pois é pelo uso, o consumo de fato do produto e, consequente avaliação ex-post do produto, que elementos importantes como a reputação, a propaganda boca a boca, a recompra, a fidelidade do consumidor ao produto vão sendo construídos e modificados. Deste modo, elementos ex-ante (lucro do consumidor) e ex-post ao consumo, pelo lado do consumidor, importam na vantagem competitiva sustentável e, também, na captura e proteção de valor.

\section{Ex Post Consumo: o Uso do Valor de uso}

Para Marx (1983), o valor do produto se realiza no próprio consumo. Para Rocha (1985), no domínio do consumo, o Homem não é apenas Homem, é Homem Rei, senhor dos desejos e comprador de bens, serviços, produtos. Pode ser a maneira para extravasar os sentimentos reprimidos, porque é necessário que todo homem possa ter sua participação e dar vazão as suas necessidades e desejos, gostos e carências.

Paralelamente, a literatura de marketing costuma distinguir cliente de consumidor de maneira que este último é a pessoa que vai utilizar, consumir, dar fim ao produto de fato. 0 produto foi criado para um certo fim e seu desempenho dependerá não apenas do produto em si, mas também da habilidade, do conhecimento e da experiência do consumidor.

O papel participativo do consumidor vem sendo cada vez mais destacado na literatura especializada, principalmente com os trabalhos de Prahalad e Ramaswamy (2000) sobre a cocriação de valor pelo consumidor. 
Para Fujioka (2009), a experiência de co-criação (não o da oferta unilateral da indústria) permite o desenvolvimento único de valores para cada indivíduo. Assim, os consumidores saem de uma posição passiva para chegar em uma posição ativa (PRAHALAD; RAMASWAMY, 2000). Como é o caso da empresa Camiseteria que vende camisetas e outros vestuários online com estampas sugeridas pelos internautas em concursos realizados pelo próprio site. Os consumidores também podem postar suas fotos vestindo as camisetas compradas e também interagindo com o site por meio das mídias sociais.

Holbrook (1996) define valor do consumidor como sendo a experiência que conta e que dá valor ao consumidor sobre o produto. Isso é fundamental para a co-criação de valor. A possibilidade de customização de produtos como um Rolls-Royce Phantom abre novas oportunidades e opções para o consumidor, o que vai gerar a necessidades da firma de expandir suas fronteiras e conhecimentos, principalmente adquirindo competências complementares as suas áreas de atuação, ou então contando com o apoio de firmas especializadas com competências e serviços que auxiliem na opção de uma configuração de benefícios exclusivos. Outro exemplo do setor automotivo é o projeto desenvolvido pela montadora italiana Fiat de um carro conceito chamado de Fiat Mio. O carro recebeu ideias e sugestões de clientes, consumidores e simpatizantes da montadora apenas pela internet, o que acabou gerando um carro conceito apresentado no salão de automóveis de São Paulo no ano de 2010. Durante os meses de agosto de 2009 a outubro de 2010 mais de dois milhões de internautas de 160 países visitaram o portal, sendo que mais de 10 mil ideias foram postadas para o Mio (Trindade, 2010).

É importante perceber que a habilidade do consumidor de co-criar o valor depende também da quantidade de informações, conhecimento, habilidades e outros recursos e competências que ele possui, tem acesso ou pode usar; isso pode gerar impactos sobre a própria sustentabilidade da vantagem competitiva, uma vez que consumidores mais exigentes vão cobrar produtos que ultrapassem o domínio da tradição e do modo costumeiro de se fazer negócio no setor. Assim, Korkman (2006) sugere uma linha de pesquisas baseadas no engajamento prático dos consumidores por meio do conjunto de ações rotinizadas, as ferramentas, o conhecimento, imagens, espaços físicos, a atmosfera do grupo, os diálogos antes, durante e depois da experiência, etc. Para Prahalad e Ramaswamy (2000), isso significa envolver e cooptar as competências, o conhecimento e a habilidade dos próprios consumidores.

Vargo (2008) observa que o termo "valor em uso" deveria ser substituído por "valor no contexto", pois o mesmo é usado em contextos sociais, culturais, etc. Por outro lado, Edvardsson, Tronvoll e Gruber (2010) enfatizam que o valor é determinado não apenas pelo valor em uso do indivíduo, mas em uma percepção social mais ampliada. Assim, eles observam a importância do significado, controle (dominação) e regras morais (legitimação) para a própria construção social da realidade e dos valores observados e experimentados.

De maneira mais relacional, para Gronroos (2000) o valor é co-criado por meio dos relacionamentos entre clientes e em partes, com a própria interação entre cliente-varejistaprodutor. Semelhantemente com Fujioka (2009) que destaca não apenas a habilidade dos administradores de receber informações dos consumidores, mas também de promover um melhor ambiente de trabalho.

Tanto a firma que desenvolve atividades de busca, armazenamento, transformação e distribuição como o consumidor que procura e consome o produto influenciam em relação aos aspectos inerentes aos valores de uso, valores de troca, uso dos valores de uso. Deste modo, é natural que as estratégias contemplem as inter-relações existentes entre aspectos da produção e da transação, da firma e do consumidor, das necessidades e dos benefícios. 


\section{Implicações Estratégicas}

A estratégia é um fenômeno complexo e parece ter se difundido ou migrado da cabeça do grande pensador estrategista para uma espécie de rede multifatorial de construção e captura, proteção e expansão de valor (Wittmann, Lübeck, Nelsis, 2013). É o valor acumulado que importa! Um exemplo desta nova situação é o "duelo" que existia entre a Encarta e a Wikipedia. A primeira era a enciclopédia pertencente à Microsoft e que dominava o setor no começo da década de 1990. Por outro lado, a Wikipedia é uma enciclopédia livre que qualquer um tem acesso e que qualquer um pode editar. Na primeira havia equipes altamente qualificadas de uma das maiores e mais bem sucedidas empresas de software da história. Na outra, havia uma comunidade de voluntários dispostos a colaborar de forma livre e espontânea para o desenvolvimento do projeto Wikipedia. 0 resultado foi que, em 2009, a Encarta foi descontinuada e a Wikipedia ainda continua progressivamente expandindo-se e melhorando devido à ajuda destes colaboradores. A busca pela vantagem competitiva e do próprio sucesso e sobrevivência depende do acúmulo de valores, seja protegendo, seja criando valor. A estratégia da Wikipedia acabou impedindo a Encarte de proteger o seu valor a ponto do seu valor de troca ficar abaixo de recompensar a empresa de maneira adequada.

Deste modo, além das clássicas atividades de procurar, manter, transformar e vender, agora também é preciso levar em consideração as atividades e as próprias percepções e sentimentos da comunidade de envolvidos e do consumidor em relação ao produto e os valores, seja de troca, seja de uso, embutidos e usados de fato por ele. Assim, o valor depende de elementos multidimensionais, sendo um processo contínuo e sistemático de influenciação entre eles. Contínuo devido ao fluxo constante de entrada, transformação, saída de produtos e recursos, bem como de negociação de transação. Além disso, sistemático, pois o fluxo obedece a certas regras ou heurísticas, seja de causa e efeito, seja de ordem dos elementos na cadeia de agregação de valor. Todavia, não se pode tornar rígido o processo, pois apesar de haver certa previsibilidade e de ter condições de mapear por meio de ferramentas, tais como os fluxos de valor da manufatura enxuta ou a dinâmica de sistemas, cada transação ou cada transformação é rodeada por características e contextos únicos. Todavia, ainda assim é possível relacionar as questões de valor com as atividades da firma e do consumidor. De maneira geral, o Quadro 2 procura expandir e complementar o Quadro anterior, inserindo o consumidor e suas relações $e x$-ante e $e x$-post consumo.

\begin{tabular}{|l|l|l|l|l|}
\hline & Atividade & Visa & Ação & $\begin{array}{l}\text { Valor } \\
\text { preponderante }\end{array}$ \\
\hline \multirow{4}{*}{ Firma } & Procurar & $\begin{array}{l}\text { Recursos com alto valor de } \\
\text { uso, mas baixo valor de troca }\end{array}$ & Capturar valor & Valor de Troca \\
\cline { 2 - 5 } & Manter & Evita a perda de valor & Proteger valor & Valor de Uso \\
\cline { 2 - 5 } & Transformar & Gerar novo valor de uso & Criar Valor & Valor de Uso \\
\cline { 2 - 5 } & Vender & $\begin{array}{l}\text { Vender os novos valores de } \\
\text { uso com o maior valor de } \\
\text { troca evitando a apropriação } \\
\text { indevida pelos compradores }\end{array}$ & $\begin{array}{l}\text { Capturar Valor } \\
\text { Proteger Valor }\end{array}$ & Valor de Troca \\
\hline Consumidor & Procurar & $\begin{array}{l}\text { Recursos com alto valor de } \\
\text { uso, mas baixo valor de troca }\end{array}$ & $\begin{array}{l}\text { Obter maior lucro do } \\
\text { consumidor }\end{array}$ & Valor de Troca \\
\cline { 2 - 5 } & Transformar & Consumir o produto & Uso do valor & Valor de Uso \\
\hline
\end{tabular}

Quadro 2 - Valor e Vantagem Competitiva 
Assim, é possível ter uma ideia mais ampla sobre a construção do valor e os elementos que podem auxiliar ou não na formação da estratégia da empresa e do produto; pode-se também tentar o gerenciamento dos diversos elementos do elo da cadeia produtiva como uma forma de acumular no final um saldo positivo de valor criado, capturado, agregado em relação às perdas existentes no próprio sistema. Outro ponto de destaque é a própria condição do produto. Este é o veículo que leva não apenas os benefícios inerentes a ele, mas também serve de 'ponte' entre a firma e o próprio consumidor. Todavia, conforme Kotler e Keller (2006), esta ponte apresenta diferentes níveis:

Benefícios Centrais: refere-se ao núcleo básico ou essencial do produto; é o conceito ou ponto de partida daquilo que o consumidor está realmente comprando ou necessitando.

Produto Básico: refere-se à 'materialização primária' dos benefícios centrais; os benefícios básicos que o produto propicia aos consumidores e pode ser entendido por meio deste questionamento: “O que o comprador está realmente comprando?" (Kotler; Armstrong, 1998, p. 190).

Produto Real: é criado a partir do anterior. Tal nível apresenta cinco particularidades: qualidade, características (acessórios, detalhes), design, marca e embalagem.

Produto Ampliado: significa exceder a expectativa do consumidor por meio do oferecimento de serviços e benefícios extras, tais como garantia, serviços de pós-venda, etc.

Produto Potencial: representa as transformações futuras que o produto pode vir a ser submetido; é onde as empresas procuram diferenciar suas ofertas de seus concorrentes (Kotler; Keller, 2006).

Para Lendrevie et al. (1993), as características dos produtos são divididas em dois grandes grupos: funcionais e de imagem. Pertencem ao primeiro as características físicas do produto, tais como: composição, desempenho técnico, qualidades organolépticas. 0 segundo grupo é composto pela imagem, marca, design, estética, a embalagem, a preocupação com as cores. Tanto o lado técnico quanto o estético auxiliam na construção dos valores como também, ou até principalmente, influenciam na percepção do valor; o que pode resultar em preços superiores. A Figura 3 procura ilustrar a questão.

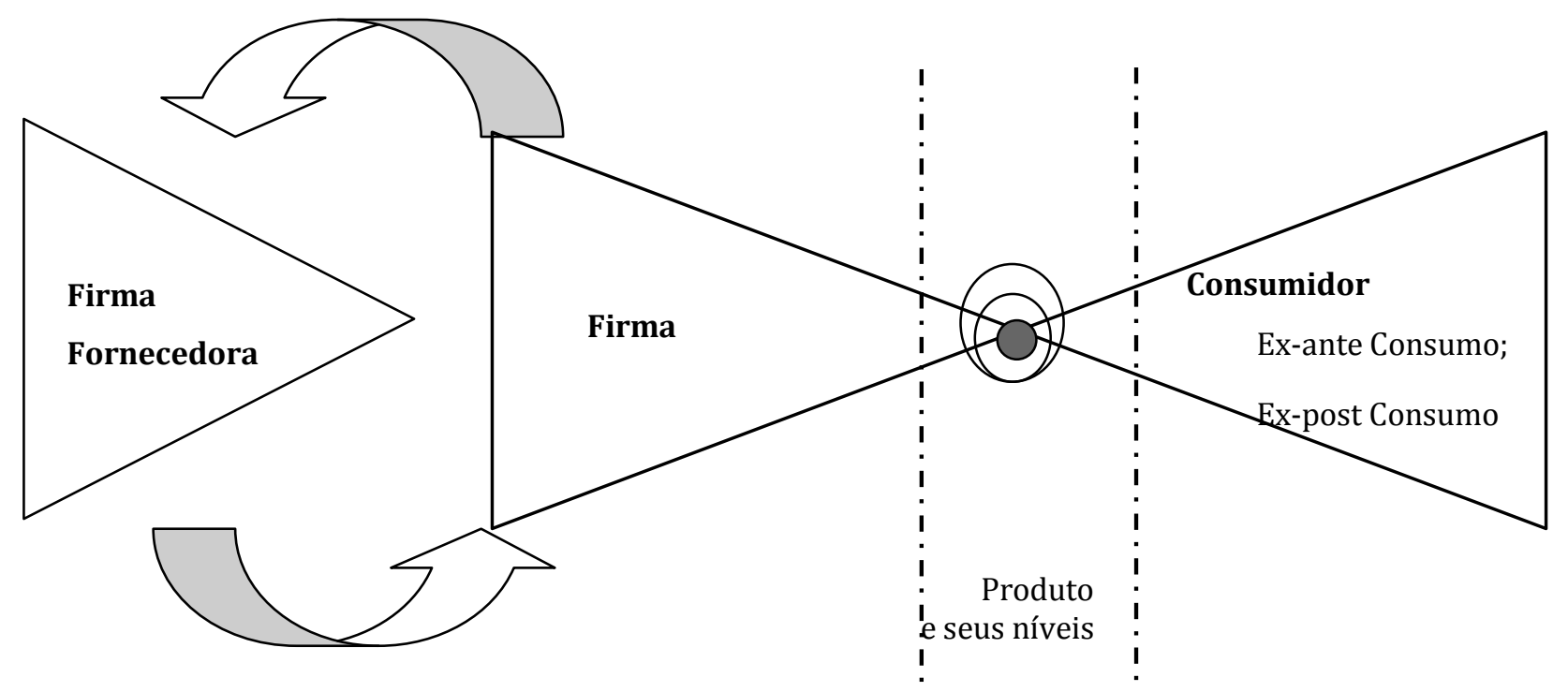

Figura 3 - Modelo de ligação estratégica entre fornecedor, firma e consumidor 
Nada adiantaria para uma empresa investir em um produto de grande eficácia técnica se não houvesse também o reconhecimento do mercado. 0 caso do boicote dos consumidores, seja por questões econômicas, seja por questões ideológicas representa uma ilustração do poder do consumidor (Cruz e Ross, 2013). Outro exemplo é o caso das tribos urbanas que representam cada vez mais fenômenos presentes no nosso dia-a-dia, principalmente devido à internet e as redes sociais (Casotti et al., 2013).

Desenvolver produtos de alta capacidade técnica sem a devida percepção do valor, seja de uso e de troca, seria como cair no erro e no fracasso do inventor da clássica estória de marketing da melhor ratoeira do mundo. Até hoje cresce grama no jardim da casa do inventor e ninguém mais sabe onde fica. Assim, é necessário não apenas a preocupação com o lado da produção como também com a transação e o consumo. Certamente a estratégia não lida com fenômeno simples e univariado; portanto, conseguir uma visão multivariada, multifacetada e nas diferentes etapas produtivas e elos da cadeia parece ser tanto um desafio quanto uma oportunidade para a agregação e proteção de valor. Mais do que uma simples empresa transformativa ou de transação, a empresa lida com aspectos pluralísticos e dinâmicos em fluxos de transformação e também, ao mesmo tempo, de manutenção e controle. Parafraseando um dito popular brasileiro, pode-se dizer que pela obtenção de pequenas porções fragmentadas de valor (adquirido, barganhado, construído, protegido, expandido), a empresa consegue acumular vantagens competitivas ao longo do tempo.

\section{Considerações Finais}

As firmas existem e por mais de um motivo. Elas são a razão de ser para o alcance da missão e também do sonho e aspirações pessoais íntimas de seu empreendedor, mas também porque são arranjos mais eficientes do que o mercado em algumas situações específicas. Assim, é por meio da coordenação eficiente dos recursos e dos fatores produtivos que ela consegue tanto agregar valor e construir produtos ou oferecer serviços como também trocá-los no mercado com recompensas financeiras ou não. Se por um lado ela apresenta atividades, tais como a busca, o armazenamento, a transformação e a venda, por outro, a firma também realiza trocas e sofre também influências do próprio consumidor. Não apenas o consumidor é o juiz do produto e da empresa, mas também pode participar ativamente até mesmo do processo de cocriação do produto. Assim, empresas como a Fiat ou a Camiseteria são exemplos de abertura e colaboração com a firma permitindo uma voz mais ativa do consumidor. A questão do valor de uso, valor de troca e também uso do valor de uso torna-se, portanto, especial. 0 valor de uso representa não apenas a parte funcional, utilitária do produto, mas também aquilo que vai suprir as necessidades e desejos do próprio consumidor. 0 valor de uso pode ser obtido tanto por meio de processos de compra da empresa quanto por meio de manutenção, transformação e distribuição (venda). Todavia, adotando-se o modelo de uma empresa produtora, o principal locus da produção ou agregação de valor está na atividade de transformação. Por outro lado, a distribuição é o locus da transação. Tanto em um lugar quanto no outro há tantos ganhos e acúmulos de valor como também possíveis perdas, seja por meio de ágios praticados pelos fornecedores, seja por meio de descontos pedidos pelos clientes. A firma e a própria estratégia depende deste fluxo contínuo e intermitente de jogos de valor. 0 importante é conseguir acumular valores positivos ao longo da trajetória e do tempo. A expansão dos níveis dos produtos, principalmente por meio do 'produto ampliado', parece ser uma forma de a empresa buscar o aumento da percepção do valor de uso e com possibilidades de melhores valores de troca. Além disso, empresas como o Wikipedia parecem ter obtido a colaboração ativa da própria comunidade de usuários para o desenvolvimento do nível de produto potencial. Assim, apesar do valor de troca ser baixo ou praticamente inexistente no caso do Wikipedia, seu valor 
de uso é muito grande, sendo reconhecido por seus usuários a ponto de seu principal concorrente ter sua produção descontinuada.

Todavia, apesar de as questões de valor (de uso, de troca) serem importantes para a estratégia e para o próprio desenvolvimento futuro da organização, ainda não há muito consenso dentro da comunidade acadêmica, principalmente devido às diferentes lentes e backgrounds de seus pesquisadores. Debates e pesquisa sobre o assunto podem auxiliar na elucidação de aspectos ainda truncados dentro da área de estratégia, sendo que o presente artigo auxilia justamente para fomentar e tentar avançar para um melhor entendimento ou sofisticação de pesquisas posteriores.

Deste modo, recomenda-se como pesquisa futura a continuidade em pesquisas que adotem o valor como critério para a vantagem competitiva, bem como uma melhor estruturação conjunta de abordagens estratégicas como a Visão Baseada em Recursos (VBR) com a Teoria dos Custos de Transação (TCT). Além disso, a cocriação de valor com a coevolução também parece ser uma medida adequada de desenvolvimento do campo. Outra possibilidade é a construção social do valor e o reconhecimento dos valores de troca. Assim, o contexto torna-se um elemento importante para o entendimento da própria estratégia e dos alinhamentos que a empresa precisa realizar para satisfazer suas necessidades e de seus consumidores. Entretanto, na questão do valor e da estratégia, dos benefícios e das necessidades, dos valores de uso e valores de troca, muitas vezes é preciso lembrar as palavras de Fernando Pessoa: "Adoramos a perfeição, porque não a podemos ter; repugna-la-íamos, se a tivéssemos. 0 perfeito é desumano, porque o humano é imperfeito".

\section{Referências:}

BACH, G.L.; FLANAGAN, R.; HOWELL, J.; LEVYM F.; LIMA, A. Microeconomics. Englewood Cliffs: Prentice Hall, 1987

BARNEY, J. B. Firms resources and sustained competitive advantage. Journal of Management, v. 17, n. 1, 1991.

BARNEY, J. B.; HESTERLY, W. Economia das Organizações: entendendo as relação entre as organizações e a análise econômica. In: Clegg, S. R.; Hardy, C.; Nord, W. R. Handbook de Estudos Organizacionais, v. 3. São Paulo: Atlas, 1998.

BOWMAN, C.; AMBROSINI, V. Value creation versus value capture: towards a coherent definition of value in strategy. British Journal of Management, v. 11, 1-15, 2000.

CASOTTI, L.; FARINA, M.; LINO, B.; AMERICANO, G. Estética e consumo: estudando duas tribos urbanas cariocas. Revista Pensamento Contemporâneo em Administração. v.7, n.1, jan./mar. 2013.

COASE, R. H. The Nature of the Firm. Economica, 4, 386-405, 1937.

CRUZ, B. DE P. A.; ROSS, S.D. Percepção de culpa no boicote de um bem de luxo. Revista Pensamento Contemporâneo em Administração. v.7, n.3, jul./set. 2013.

DIERICKX, I.; COOL, K. Asset stock accumulation and sustainability of competitive advantage. Management Science, 35, 12, 1989.

DODDS, W.B., MONROE, K.B., GREWAL, D. Effects of price, brand, and store information on buyers' product evaluations. Journal of Marketing Research, 28(3), 307-319, 1991.

EDVARDSSON, B.; TRONVOLL, B.; GRUBER, T. Expanding understanding of service exchange and 
value co-creation: a social construction approach. J. of the Acad. Mark. Sci. April, 2010. FUJIOKA, Y. A consideration of the processo f co-creation of value with customers. Artif. Life Robotics, 14:101-103, 2009.

HAMEL, G.; PRAHALAD, C.K. Competindo pelo Futuro: Estratégias inovadoras para obter o controle do seu setor e criar os mercados de amanhã. Rio de Janeiro, Campus, 1995.

HOLBRO0K, M. B. Customer Value: A Framework for Analysis and Research. Advances in Consumer Research, 23(1), 138-142, 1996.

HUNT, S.; MORGAN, R.M. The comparative advantage theory of competition. Journal of Marketing, v.59, 1-15, April, 1995.

KORKMAN, O. Customer Value Formation in Practice: A Practice-Theoretical Approach. Report A155. Helsinki: Hanken Swedish School of Economics Finland, 2006.

KOTLER, P.; ARMSTRONG, G. Princípios de marketing. Rio de Janeiro: Prentice-Hall, 1998.

KOTLER, P.; KELLER, K.L. Marketing Management. New Jersey: Prentice-Hall, 2006.

LENDREVIE, J. et al. Mercator: teoria e prática do marketing. Lisboa: Dom Quixote, 1993.

LEPAK, D.P.; SMITH, K.G.; TAYLOR, M.S. Value creation and value capture: a multilevel perspective. Academy of Management Review. v.32, n.1, 180-194, 2007.

LIPPMAN, S. A.; RUMELT, R. P.Uncertain imitability: an analysis of interfirm differences in efficiency under competition. The Bell Journal of Economics, 13, 2, 1982.

MARX, K. O capital. Vol. I, tomo I. São Paulo: Abril Cultural, 1983.

MINTZBERG, H.; VAN DER HEYDEN, L. Re-viewing the organization. Ivey Business Journal. September/October, 2000.

PENROSE, E. The theory of the growth of the firm. Oxford: Oxford University Press, 1995.

PETERAF, M. A. The cornerstone of competitive advantage: a resource based view. Strategic Management Journal, 14, 3, 1993.

PETERS, T. As pequenas grandes coisas. Rio de Janeiro: Agir, 2011.

PORTER, M. E. Competitive Strategy. New York: Free Press, 1980.

PORTER, M. E. Vantagem Competitiva: Criando e Sustentando um Desempenho superior. Rio de Janeiro: Editora Campus, 1990.

PORTER, M. E. What is strategy? Harvard Business Review, 74, 1996.

PRAHALAD, C.K; RAMASWAMY, V. 0 futuro da competição: como desenvolver diferenciais inovadores em parcerias com os clientes. Rio de Janeiro: Elsevier, 2004.

PRAHALAD, C.K; RAMASWAMY, V. Co-opting customer competence. Harvard Business Review, 79-87, January-February, 2000.

ROCHA, E. P. Magia e capitalismo: Um estudo antropológico da publicidade. São Paulo: Braziliense, 1985.

RUMELT, R .P. Towards a strategic theory of the firm. In: Lamb, R. B. Competitive Strategic Management. Prentice Hall: Englewood Cliffs, 1984.

SCHIFFMAN, L.G.; KANUK, L.L. Comportamento do consumidor. Rio de Janeiro: Livros Técnicos e Científicos, 2000.

SMITH, A. A riqueza das nações. São Paulo: ed. Abril, 1983. 
TEECE, D. J.; PISANO, G.; SHUEN, A. Dynamic capabilities and strategic management. Strategic Management Journal, 18, 7, 1997.

TRINDADE, F. 2010. Salão do automóvel: Fiat mostra o conceito Fiat Mil (FCC III). Documento eletrônio, 03 de Novembro de 2010. Acessado em: 18 de Dezembro de 2014. Disponível em: http://carplace.virgula.uol.com.br/salao-do-automovel-fiat-mostra-o-conceito-fiat-mio-fcc-iii/

VARGO, S. L. Customer Integration and Value Creation: Paradigmatic Traps and Perspectives. Journal of Service Research, 11 (2), 211-21, 2008.

VERONA, G. A resource-based view of product development. Academy of Management Review, v.24, n.1, 1999.

WERNERFELT, B. A resource-based view of the firm. Strategic Management Journal, v. 5. n.2, Apr./Jun 1984.

WILLIAMSON, O. E. The Economic Institutions of Capitalism. New York: Free Press, 1985.

WILLIAMSON, O. E. Comparative Economic Organization: The Analysis of Discrete Structural Alternatives. Administrative Science Quarterly, 36, 2, 269-296, 1991a.

WILLIAMSON, O. E. Strategizing, Economizing, and Economic Organization. Strategic Management Journal, 12 (S2), 75-94, 1991b.

WITTMANN, M.L.; LÜBECK, R.M.; NELSIS, V.DE M. Uma visão não-linear sobre estratégia empresarial pelo prisma da complexidade. Revista Pensamento Contemporâneo em Administração. v.7, n.4, out./dez. 2013. 